\title{
Synthesis, effect of substituents on the regiochemistry and equilibrium studies of tetrazolo[1,5-a]pyrimidine/2-azidopyrimidines
}

\author{
Elisandra Scapin ${ }^{1}$, Paulo R. S. Salbego ${ }^{2}$, Caroline R. Bender ${ }^{2}$, Alexandre R. Meyer², \\ Anderson B. Pagliari ${ }^{2}$, Tainára Orlando², Geórgia C. Zimmer ${ }^{2}$, Clarissa P. Frizzo ${ }^{2}$, \\ Helio G. Bonacorso ${ }^{2}$, Nilo Zanatta ${ }^{2}$ and Marcos A. P. Martins ${ }^{* 2}$
}

\section{Full Research Paper}

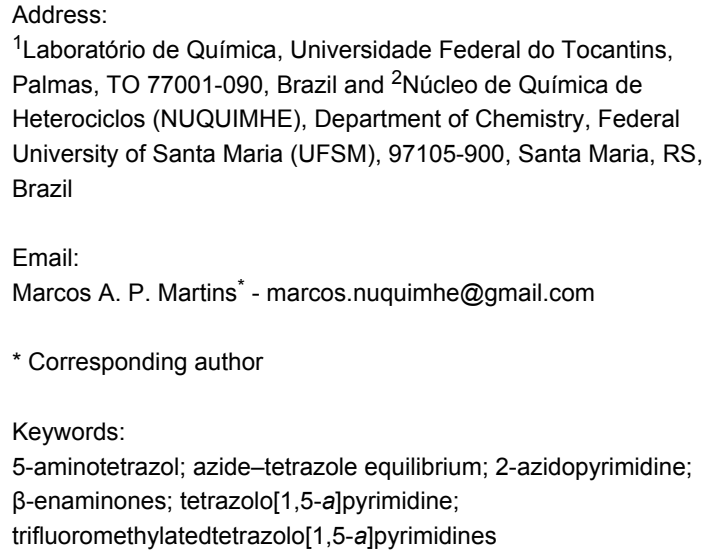

\author{
Beilstein J. Org. Chem. 2017, 13, 2396-2407. \\ doi:10.3762/bjoc. 13.237 \\ Received: 15 July 2017 \\ Accepted: 05 October 2017 \\ Published: 10 November 2017 \\ Associate Editor: T. J. J. Müller \\ (C) 2017 Scapin et al.; licensee Beilstein-Institut. \\ License and terms: see end of document.
}

\begin{abstract}
An efficient synthesis methodology for a series of tetrazolo[1,5-a]pyrimidines substituted at the 5- and 7-positions from the cyclocondensation reaction $[\mathrm{CCC}+\mathrm{NCN}]$ was developed. The NCN corresponds to 5 -aminotetrazole and CCC to $\beta$-enaminone. Two distinct products were observed in accordance with the $\beta$-enaminone substituent. When observed in solution, the compounds can be divided into two groups: (a) precursor compounds with $\mathrm{R}=\mathrm{CF}_{3}$ or $\mathrm{CCl}_{3}$, which leads to tetrazolo[1,5-a]pyrimidines in high regioselectivity with $\mathrm{R}$ at the 7-position of the heterocyclic ring; and (b) precursor compounds with $\mathrm{R}=$ aryl or methyl, which leads to a mixture of compounds, tetrazolo[1,5-a] pyrimidines ( $\mathrm{R}$ in the 5-position of the ring) and 2-azidopyrimidines ( $\mathrm{R}$ in the 4-position of the ring), which was attributed to an equilibrium of azide-tetrazole. In the solid state, all compounds were found as 2-azidopyrimidines. The regiochemistry of the reaction and the stability of the products are discussed on the basis of the data obtained by density functional theory (DFT) for energetic and molecular orbital (MO) calculations.
\end{abstract}

\section{Introduction}

Tetrazolo[1,5- $a]$ pyrimidines have attracted attention in the pharmaceutical field due to their significant potential to exhibit antitumor, antimicrobial, and antioxidant activities [1,2]. In addition to acting as a stimulant of the central nervous system [3], this class of substances plays an important role in drugs that are used to treat obesity, diabetes, hypertension, coronary heart disease, thyroid cancer, and hepatitis B virus [4-13].

Although many synthetic procedures used to obtain azolopyrimidines have been described in the literature [1,14-16], the syn- 
thesis of tetrazolo[1,5- $a]$ pyrimidines, especially those that are formed from 5-aminotetrazole, such as 1,3-binucleophile synthons, have not been sufficiently discussed [17]. Today, several existing methods are known to have several disadvantages, including long reaction time, the use of harmful solvents, and multistep synthesis [18,19].

Moreover, researchers in the 1960s and 1970s reported the existence of an azide-tetrazole equilibrium in many heterocyclic systems, namely tetrazolopyridines, tetrazolopyridazines, tetrazolopyrimidines, tetrazoloazines, and tetrazolopurines. Both tetrazole and azide have different chemical properties. Among other factors, the nature of the substituents, solvent, temperature, and physical state of the compound (solid state or solution) are the properties that have the most influence on the azide-tetrazole equilibrium [20-28].

A comprehensive understanding of the azide-tetrazole equilibrium is of great interest from a pharmacological point of view. A broader control and modulation of the equilibrium can lead to a specific compound to prevent undesirable pharmacokinetics and biological properties arising from the differences in the chemical structure.

Our research group previously demonstrated an efficient and regioselective synthesis of pyrazolo[1,5-a]pyrimidines and aryl[heteroaryl]pyrazolo[1,5-a]pyrimidines in acetic acid under reflux. The regioselectivity was attributed to the high nucleophilicity of the amino group in 3-amino-5-methyl- $1 H$-pyrazole and the high electrophilicity of the $\beta$-carbon atom of the enone, both soft sites of the starting materials [29]. In recent research, we developed an efficient method to obtain 1,2,4-triazolo[1,5a]pyrimidines from the cyclocondensation reaction of $1,1,1$ trifluoro-4-metoxy-3-alken-2-one or $\beta$-enaminones with 5-amino-1,2,4-triazole. The methodology using ultrasound irradiation promoted shorter reaction times, high regioselectivity, and excellent yields, when compared with conventional thermal heating [30]. Presently, we demonstrate an eco-friendly synthesis of 5- and 7-substituted tetrazolo[1,5-a]pyrimidine isomers, in good to excellent yields, using ionic liquids and water as solvents, and short reaction times. In addition, 5-substituted isomers have proved to be excellent models in carrying out a thorough investigation of the azide-tetrazole equilibrium mechanism by density functional theory (DFT) and various experimental methods (e.g., NMR, SCXRD, PXRD, FTIR).

Therefore, this study aims to (i) propose an efficient methodology for the synthesis of tetrazolo[1,5- $a$ pyrimidines substituted at the 5- and 7-positions of the heterocyclic ring; (ii) observe the regiochemistry of the cyclocondensation reaction and the effect of the substituent on the $\beta$-enaminone precursor and (iii) eluci- date the azide-tetrazole equilibrium when the compound is in solid form or dissolved in distinct solvents. The tetrazolo[1,5a]pyrimidine synthesis was conducted from a cyclocondensation reaction of the type $[\mathrm{CCC}+\mathrm{NCN}]$, in which the $\mathrm{CCC}$ block is a series of $\beta$-dimethylamino vinyl ketones, and the NCN block is 5 -aminotetrazole.

\section{Results and Discussion Synthesis of tetrazolo[1,5-a]pyrimidines}

The $\beta$-dimethylamino vinyl ketones ( $\beta$-enaminones) were synthesized using methodologies previously described by our research group [31]. In order to achieve better reaction conditions for the preparation of tetrazolo[1,5-a]pyrimidines, the reaction of $\beta$-enaminone 1a with 5 -aminotetrazole (2) was carried out under several conditions using conventional solvents and ionic liquids (ILs) to provide 5-phenyltetrazolo[1,5a]pyrimidine (3a).

Two conditions in which the product exceeded $80 \%$ yield were found: (i) toluene reflux in the presence of $\mathrm{HCl}$ for $16 \mathrm{~h}$ (entry 2, Table 1), and (ii) ionic liquid [HMIM][TsO] at $120^{\circ} \mathrm{C}$ in the presence of $\mathrm{HCl}$ for $5 \mathrm{~min}$ or $2.5 \mathrm{~h}$ (entries 7 and 8, respectively, Table 1). Nevertheless, the use of the IL [HMIM][TsO] proved advantageous when compared to toluene due to the considerable difference in reaction time (IL (5 $\mathrm{min}$ ) in comparison with toluene $(16 \mathrm{~h})$ ). This can be attributed to the significant stabilization of charges in the activated complex of the reaction promoted by charged [HMIM][TsO]. Other advantages regarding special properties (such as high thermal stability and low volatility) of ILs can be considered. Reactions in $[\mathrm{BMIM}]\left[\mathrm{BF}_{4}\right]$ and $[\mathrm{HMIM}][\mathrm{TsO}]$ using $p$-toluenesulfonic acid $(p$-TsO) as a catalyst were unsuccessful and have been omitted from Table 1.

The best conditions that were found for 1a and 5-aminotetrazole (2) were used for the reaction of $\mathbf{2}$ with $\beta$-enaminones $\mathbf{1 b}-\mathbf{i}$ (Table 2). The products formed from the reaction of $\mathbf{1 a - g}$ with 5 -aminotetrazole were detected as a tetrazolo[1,5-a]pyrimidine $\rightleftharpoons$-azidopyrimidine $(3 \rightleftharpoons 4)$ equilibrium in solution, which were identified by NMR. On the other hand, the reaction of $\mathbf{1 h}$,i with 5-aminotetrazole (2) was highly regioselective and yielded tetrazolo[1,5- $a$ ] pyrimidines $\mathbf{5 h}, \mathbf{i}$, in which $\mathrm{R}=\mathrm{CF}_{3}$ and $\mathrm{CCl}_{3}$ and presented exclusively $\mathrm{R}$ at the 7-position of the heterocyclic ring (Table 2). The tetrazolo[1,5-a]pyrimidine $\rightleftharpoons$-azidopyrimidine $(3 \rightleftharpoons 4)$ equilibrium will be discussed in detail later in this article. All products were formed in good to excellent yields (40-96\%). To the best of our knowledge, all synthesized compounds, with the exception of $\mathbf{3 a : 4 a}$, $\mathbf{3 g}: \mathbf{4 g}$, and $\mathbf{5 h}[21,32]$, have not been previously described in the literature. Acid catalysts and conventional organic solvents were used for the cyclization of enaminones [33,34]. This 
Table 1: Reaction conditions for the synthesis of compounds $\mathbf{3 a} / \mathbf{4 a}$.

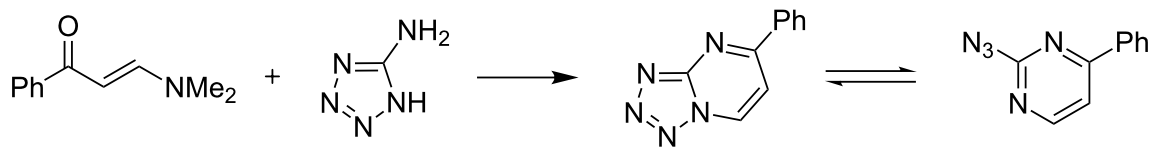

$1 a$

2

$3 a$

$4 a$

\begin{tabular}{|c|c|c|c|c|c|}
\hline entry & solvent ${ }^{a}$ & temp. $\left({ }^{\circ} \mathrm{C}\right)$ & time & $\operatorname{acid}^{b}$ & yield $(\%)^{c}$ \\
\hline 1 & $\mathrm{AcOH}$ & reflux & $16 \mathrm{~h}$ & - & 0 \\
\hline 2 & toluene & reflux & $16 \mathrm{~h}$ & $\mathrm{HCl}$ & 83 \\
\hline 3 & {$[\mathrm{BMIM}]\left[\mathrm{BF}_{4}\right]$} & 120 & $6 \mathrm{~h}$ & - & 0 \\
\hline 4 & {$[\mathrm{BMIM}]\left[\mathrm{BF}_{4}\right]$} & 120 & $5 \mathrm{~min}$ & $\mathrm{HCl}$ & 0 \\
\hline 5 & {$[\mathrm{BMIM}]\left[\mathrm{BF}_{4}\right]$} & 120 & $2.5 \mathrm{~h}$ & $\mathrm{HCl}$ & 54 \\
\hline 6 & {$[\mathrm{BMIM}]\left[\mathrm{BF}_{4}\right]$} & 120 & $6 \mathrm{~h}$ & $\mathrm{HCl}$ & 60 \\
\hline 7 & [HMIM][TsO] & 120 & $5 \min$ & $\mathrm{HCl}$ & 82 \\
\hline 8 & [HMIM][TsO] & 120 & $2.5 \mathrm{~h}$ & $\mathrm{HCl}$ & 80 \\
\hline 9 & [HMIM][TsO] & 120 & $6 \mathrm{~h}$ & $\mathrm{HCl}$ & 63 \\
\hline
\end{tabular}

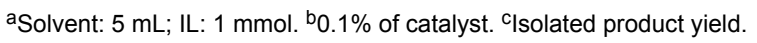

Table 2: Synthesis of compounds $3 \mathbf{a}-\mathbf{g}, \mathbf{4 a - g}$ and $\mathbf{5 h}, \mathbf{i}$.<smiles>[R]C(=O)C=CN(C)C</smiles>

1a-i<smiles>Nc1nnn[nH]1</smiles>

2

$\mathrm{R}=$ aryl, $\mathrm{CF}_{3}, \mathrm{CCl}_{3}$

i) $[\mathrm{HMIM}]\left[\mathrm{TsO}, \mathrm{HCl}(0.1 \%), 5 \mathrm{~min}, 120^{\circ} \mathrm{C}\right.$.

ii) toluene, $\mathrm{HCl}$, reflux, $16 \mathrm{~h}$

\begin{tabular}{|c|c|c|c|c|}
\hline \multirow[t]{2}{*}{ product } & \multirow[t]{2}{*}{$\mathrm{R}$} & \multicolumn{2}{|c|}{ yield $^{a}(\%)$} & \multirow{2}{*}{$\begin{array}{c}\text { molar ratio }^{\mathrm{b}} \\
3: 4\end{array}$} \\
\hline & & [HMIM][TsO] & toluene & \\
\hline $3 a: 4 a$ & $\mathrm{Ph}$ & 82 & 87 & $84: 16$ \\
\hline $3 b: 4 b$ & $4-\mathrm{F}-\mathrm{C}_{6} \mathrm{H}_{4}$ & 83 & 85 & $79: 21$ \\
\hline $3 c: 4 c$ & 4- $\mathrm{Cl}-\mathrm{C}_{6} \mathrm{H}_{4}$ & 91 & 88 & $85: 15$ \\
\hline 3d:4d & 4- $\mathrm{Br}-\mathrm{C}_{6} \mathrm{H}_{4}$ & 95 & 87 & $79: 21$ \\
\hline $3 e: 4 e$ & $4-\mathrm{I}-\mathrm{C}_{6} \mathrm{H}_{4}$ & 86 & 96 & $89: 11$ \\
\hline $3 f: 4 f$ & $4-\mathrm{CH}_{3}-\mathrm{C}_{6} \mathrm{H}_{4}$ & 89 & 91 & $93: 7$ \\
\hline $3 g: 4 g$ & $4-\mathrm{OCH}_{3}-\mathrm{C}_{6} \mathrm{H}_{4}$ & 93 & 78 & $94: 6$ \\
\hline $5 \mathrm{~h}$ & $\mathrm{CF}_{3}$ & 70 & 40 & $100^{c}$ \\
\hline $5 i$ & $\mathrm{CCl}_{3}$ & 68 & 77 & $100^{c}$ \\
\hline
\end{tabular}

alsolated product yield. ${ }^{\mathrm{b}}$ The $3: 4$ molar ratio was calculated based on the aromatic hydrogens in the ${ }^{1} \mathrm{H}$ NMR spectrum using DMSO- $d_{6}$ for products

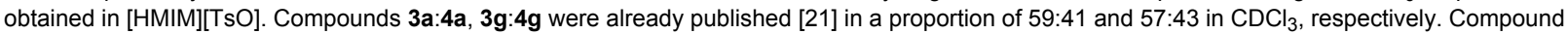
$5 \mathrm{~h}$ was previously observed as 1,7 -isomer [32]. ${ }^{C}$ Was only observed as a single product in $\mathrm{CDCl}_{3}$. 
method provided good yields and regioselectivity using a simple catalyst and an IL as the solvent. Notably, not only the reaction time was short, but the purification process is simple.

\section{The regiochemistry \\ of tetrazolo[1,5-a]pyrimidines}

The regiochemistry of tetrazolo[1,5-a]pyrimidines can be verified by ${ }^{1} \mathrm{H}$ NMR spectroscopy. The substituted tetrazolo[1,5a]pyrimidines found in the literature $[21,32]$ presented coupling constants of ${ }^{3} J_{\mathrm{H}-\mathrm{H}}=6.9-7.3 \mathrm{~Hz}$ for $\mathrm{H} 6-\mathrm{H} 7$, and ${ }^{3} J_{\mathrm{H}-\mathrm{H}}=4.2-4.8 \mathrm{~Hz}$ for H5-H6. The coupling constant for compound $\mathbf{3 a}$ is ${ }^{3} J_{\mathrm{H}-\mathrm{H}}=7.3 \mathrm{~Hz}$, while compound $\mathbf{5} \mathbf{h}$ has a coupling constant of ${ }^{3} J_{\mathrm{H}-\mathrm{H}}=4.9 \mathrm{~Hz}$, which characterizes the substitution at the 5-position and 7-position of the heterocyclic ring, respectively (Figure 1).

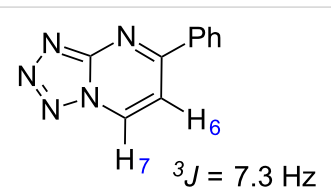

(a)

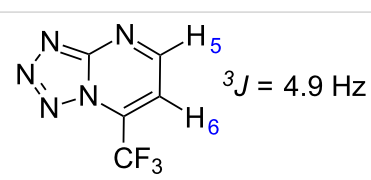

(b)
Figure 1: Hydrogen coupling constants $\left({ }^{3} J_{\mathrm{H}-\mathrm{H}}\right)$ of $(\mathrm{a}) \mathrm{H} 6-\mathrm{H} 7$ for $3 a$ and (b) $\mathrm{H} 5-\mathrm{H} 6$ for $\mathbf{5 h}$.

The formation of 7-trihalomethyl-substituted $\left(\mathrm{R}=\mathrm{CF}_{3}\right.$ and $\mathrm{CCl}_{3}$ ) tetrazolo[1,5-a]pyrimidine when $\beta$-enaminones were reacted with 5 -aminotetrazole showed that the structure of the $\mathrm{R}$ group affects the regiochemistry of the products formed.

The $\beta$-enaminones $\mathbf{1 a}-\mathbf{g}(\mathrm{R}=$ aryl $)$ result predominantly in 5 -aryl-substituted tetrazolo[1,5- $a$ ]pyrimidines $\mathbf{3 a}-\mathbf{g}$. $\beta$-Enaminones $\mathbf{1 h}, \mathbf{i}\left(\mathrm{R}=\mathrm{CF}_{3}\right.$ and $\left.\mathrm{CCl}_{3}\right)$ result in a highly regioselective synthesis of tetrazolo[1,5- $a$ ]pyrimidines $\mathbf{3 h}, \mathbf{i}$ with $\mathrm{CX}_{3}$ groups at the 7-position of the fused pyrimidine ring.

The well-defined regiochemistry of these reactions, according to the substituent, can be understood by determination of the LUMO coefficients of the carbonyl (C1) and the $\beta$-carbon (C3) of the $\beta$-enaminones. The LUMO coefficient values for neutral and conjugated acids of $\beta$-enaminones with $R=$ phenyl (1a) and $\mathrm{CF}_{3}$ (1) $)$ were determined using the Gaussian 09 software package [35] and calculated at B3LYP/cc-pVTZ level of theory (Figure 2).

Under neutral conditions, the highest LUMO coefficient in the $\beta$-enaminones with $\mathrm{R}=$ phenyl and $\mathrm{CF}_{3}$ can be found at the $\beta$-carbon $\mathrm{C} 3$ (Figure 2a). Under acidic conditions, in which the reactions were performed, $\mathrm{C} 1$ is the carbon with the highest LUMO coefficient $(0.235)$ when $R=$ phenyl (Figure $2 b$ ). Consequently, the first nucleophilic attack from the amino group of 5-aminotetrazole occurs at $\mathrm{C} 1$, leading to the formation of the 5-aryl-substituted compound 3a. On the other hand, when $\mathrm{R}=\mathrm{CF}_{3}$, the highest LUMO coefficient (0.262) is located at the $\mathrm{C} 3$ carbon of the $\beta$-enaminone (Figure $2 \mathrm{~b}$ ). Therefore, the initial nucleophilic attack leads to the formation of the 7-trifluoromethyl-substituted compound $\mathbf{5 h}$. The first nucleophilic attack from the amino group of 5-aminotetrazole was evidenced by HOMO coefficient calculations (Table S3 in Supporting Information File 1). The highest HOMO coefficient for the $\mathrm{NH}_{2}$ group indicates the superior nucleophilicity of the $\mathrm{NH}_{2}$ group in the aminotetrazole molecule. A scheme that illustrates the first nucleophilic attack that leads to different isomers according to the $\beta$-enaminone substituent can be seen in Figure S1 in Supporting Information File 1.

The synthesis of tetrazolo[1,5-a]pyrimidines $\mathbf{3 a}-\mathbf{g}$ and 2-azidopyrimidines $\mathbf{4 a}-\mathbf{g}$ were confirmed from the ${ }^{1} \mathrm{H}$ and ${ }^{13} \mathrm{C}$ NMR spectra and mass spectrometry. Chemical shift assignments and coupling constants of pyrimidine ring hydrogens were compared with compounds $3 \mathbf{a}, \mathbf{4 a}, \mathbf{3 g}, \mathbf{4 g}$, and $\mathbf{5 h}$ described in the literature [21,32]. The HMQC and HMBC ${ }^{1} \mathrm{H}-{ }^{13} \mathrm{C}$ were carried out in order to confirm the signal attributions (see Figures S5 and S6 in Supporting Information File 1).

The ${ }^{1} \mathrm{H}$ NMR spectra of $\mathbf{3 a}-\mathbf{g}: \mathbf{4 a}-\mathbf{a}$ show the aromatic protons $\mathrm{H} 6$ and $\mathrm{H} 7$ as doublets in the region between 8.11-8.24 ppm and 9.69-9.82 ppm, respectively, with ${ }^{3} J_{\mathrm{H}-\mathrm{H}}=7.3 \mathrm{~Hz}$ attri-

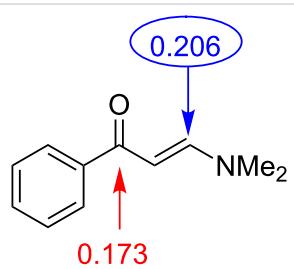

$1 \mathbf{a}$

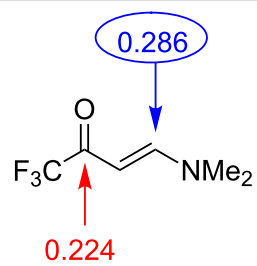

1h

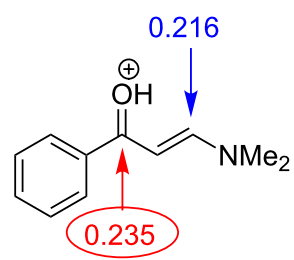

$1 \mathrm{a}$<smiles>CN(C)CC(C(=O)O)C(=O)O</smiles>

$1 \mathrm{~h}$

(a)

(b) 
buted to 5-aryl-substituted tetrazolo[1,5-a]pyrimidines. The 4a-g signals show the H5 and H6 aromatic hydrogens as doublets at 7.78-7.89 ppm and 8.67-8.79 ppm, respectively, where ${ }^{3} J_{\mathrm{H}-\mathrm{H}}=5.3 \mathrm{~Hz}$ characterizes the azide derivatives. The analysis of the ${ }^{1} \mathrm{H}$ NMR data of compounds $\mathbf{5 h}, \mathbf{i}$ shows the aromatic protons $\mathrm{H} 5$ and $\mathrm{H} 6$ as doublets in the region between $7.38-7.67 \mathrm{ppm}$ and $8.80-8.85 \mathrm{ppm}$, respectively. The ${ }^{3} J_{\mathrm{H}-\mathrm{H}}$ coupling constants of the aromatic $\mathrm{H} 5$ and $\mathrm{H} 6$ protons are around 4.8-5.2 Hz, which is a characteristic of the 7-substituted compound.

The ${ }^{13} \mathrm{C}$ NMR spectra of $\mathbf{3 a}-\mathbf{g}: \mathbf{4 a}-\mathbf{g}$ show C6 from $\delta 109.7$ to $110.9, \mathrm{C} 7$ from $\delta 135.1$ to $143.3, \mathrm{C} 3 \mathrm{a}$ from $\delta 154.7$ to 155.3 , and the carbon $\mathrm{C} 5$ from $\delta 163.4$ to 165.0 , respectively. The ${ }^{13} \mathrm{C}$ NMR data for $\mathbf{4 a}-\mathbf{g}$ show C5 from $\delta 112.7$ to 113.5 , C6 from $\delta 135.5$ to $160.9, \mathrm{C} 2$ from $\delta 160.3$ to 163.9 , and $\mathrm{C} 4$ from $\delta 163.0$ to 167.4 , respectively. The analysis of the ${ }^{13} \mathrm{C}$ NMR data of compounds $\mathbf{5 h}, \mathbf{i}$ shows C6 from $\delta 111.3$ to $112.3, \mathrm{C} 7$ from $\delta 157.7$ to $161.5, \mathrm{C} 3 \mathrm{a}$ from $\delta 161.5$ to 162.3 , and $\mathrm{C} 5$ from $\delta 163.2$ to 168.0 , respectively.

\section{The equilibrium of tetrazolo[1,5-a]pyrimidines in solution}

As previously mentioned, the products obtained from the reaction of 5-aminotetrazole with $\mathbf{1 a -} \mathbf{g}$ are observed as a mixture of compounds 3a-g:4a-g based on the ${ }^{1} \mathrm{H}$ and ${ }^{13} \mathrm{C}$ NMR spectra performed in DMSO- $d_{6}$. These ${ }^{1} \mathrm{H}$ and ${ }^{13} \mathrm{C}$ NMR analyses of 3d:4d in DMSO- $d_{6}$ showed a mixture of tetrazolo[1,5- $a$ ]pyrimidine $\mathbf{3 d}$ and 2-azidopyrimidine $\mathbf{4 d}$, which suggested the existence of a tetrazolo[1,5-a]pyrimidine $\rightleftharpoons 2$-azidopyrimidine equilibrium (3d $\rightleftharpoons$ 4d, Figure 3a,b).

In solution, the tetrazole-azido equilibrium is influenced by the polarity of the solvent. Upon increasing the solvent polarity, an increase in the amount of the tetrazole form in equilibrium is usually observed $[28,36]$. In general, the tetrazole form $\mathbf{3 a} \mathbf{a}-\mathbf{g}$ is predominant in the mixture at a proportion greater than $4: 1$ relative to the azide form $4 \mathbf{a}-\mathbf{g}$. The molar ratio of $\mathbf{3 a}-\mathbf{g}: \mathbf{4 a}-\mathbf{g}$, which was obtained from the ${ }^{1} \mathrm{H}$ NMR using DMSO- $d_{6}$ as a solvent, is presented in Table 2. Although the products 3a-g:4a-g have low solubility in $\mathrm{CDCl}_{3}$, it was possible to record the ${ }^{1} \mathrm{H}$ NMR spectrum of the mixture $\mathbf{3 d}: \mathbf{4 d}$ in this solvent. From the ${ }^{1} \mathrm{H}$ NMR, it was possible to determine that over $90 \%$ of the mixture is in the form of 2-azidopyrimidine $4 \mathbf{d}$ in $\mathrm{CDCl}_{3}$. This proves the effect of the solvent in the tetrazolo[1,5a]pyrimidine $\rightleftharpoons$-azidopyrimidine equilibrium. The highly polar DMSO- $d_{6}$ favors the ring closure to form tetrazolo[1,5a]pyrimidines in larger quantities (3d:4d in a proportion of $80: 20$ ). On the other hand, the less polar solvent $\mathrm{CDCl}_{3}$ induces the formation of 2-azidopyrimidine $\mathbf{4 d}$ at a proportion of 10:90. Here, the ring is opened to form the azide group bonded in the pyrimidine ring. This result is in agreement with the literature data [20-22,24-27,32].

To corroborate with the data, the dipole moment $(\mu)$ of two forms (3a and 4a) were estimated using the Gaussian 09 software package [35]. The dipole moment found for 3a and $\mathbf{4 a}$ was $7.47 \mathrm{D}$ and $3.83 \mathrm{D}$, respectively. These results reveal why the tetrazole form is favored in DMSO- $d_{6}$ when compared to $\mathrm{CDCl}_{3}$, since the dipole moment of the DMSO- $d_{6}$ is greater than the dipole moment of $\mathrm{CDCl}_{3}$, in addition to being able to stabilize the tetrazole form more effectively. Moreover, the results from quantum mechanical calculation confirmed that the tetrazole 3a form is $2.98 \mathrm{kcal} \mathrm{mol}^{-1}$ more stable in DMSO- $d_{6}$ when compared to its stability in $\mathrm{CDCl}_{3}$. A study of the azide-tetrazole equilibrium in several furo[2,3-e][1,5-c]pyrimidines was also performed by Sirakanyan et al. [36]. They showed that upon increasing the solvent polarity of $\mathrm{CCl}_{4}(\varepsilon 2.3)$ to DMSO- $d_{6}(\varepsilon 46.7)$, the amount of the tetrazolo form increases (from $6 \%$ to $93 \%$ ) in the equilibrium. These data corroborate the results herein regarding the influence of the solvent. It is important to note that the equilibrium is only established when the tetrazolo[1,5-a]pyrimidine is 5-substituted. 7 -substituted compounds $\mathbf{5 h}$,i were obtained as single products.

Recently, our research group demonstrated a highly regioselective synthesis of a series of trifluoromethylated tetrazolo[1,5a]pyrimidines with potent antimicrobial activity [37]. The reaction between several $\beta$-alkoxyvinyl trifluoromethyl ketones $\left[\mathrm{CF}_{3} \mathrm{C}(\mathrm{O}) \mathrm{CH}=\mathrm{C}(\mathrm{R}) \mathrm{OCH}_{3}\right]$ (in which $\mathrm{R}=\mathrm{Ph}, 4-\mathrm{F}-\mathrm{C}_{6} \mathrm{H}_{4}$, $4-\mathrm{Cl}-\mathrm{C}_{6} \mathrm{H}_{4}, \quad 4-\mathrm{Br}-\mathrm{C}_{6} \mathrm{H}_{4}, 4-\mathrm{I}-\mathrm{C}_{6} \mathrm{H}_{4}, 4-\mathrm{CH}_{3}-\mathrm{C}_{6} \mathrm{H}_{4}$, 4- $\mathrm{OCH}_{3}-\mathrm{C}_{6} \mathrm{H}_{4}$, thien-2-yl, 4- $\mathrm{Ph}-\mathrm{C}_{6} \mathrm{H}_{4}, \mathrm{CH}_{3}$ ) and 5-aminotetrazole, by using conventional heating in an oil bath or microwave irradiation, was performed in IL. Here, only the 5-trifluoromethyl-substituted tetrazolo[1,5-a]pyrimidines $\mathbf{6 a -} \mathbf{g}$ were obtained in all cases. Some important structures for the current study are depicted in Table 3 . The results were correlated with LUMO coefficient data of $\beta$-alkoxyvinyl trifluoromethyl ketones, in which the first nucleophilic attack of the 5-aminotetrazole amino group occurs in the C4 [37]. The absence of the tetrazolo[1,5-a]pyrimidine $\rightleftharpoons 2$-azidopyrimidine equilibrium in solution in $\mathrm{CDCl}_{3}$ or DMSO- $d_{6}$, in this case, can be attributed to the presence of the $\mathrm{CF}_{3}$ group at the 7-position of the ring. The energy data from DFT calculations for $\mathbf{6 a}$ in $\mathrm{CDCl}_{3}$ $\left(8.92 \mathrm{kcal} \mathrm{mol}^{-1}\right)$ and DMSO- $d_{6}\left(7.65 \mathrm{kcal} \mathrm{mol}^{-1}\right)$ indicate that the tetrazole form is more stable than the azide in both solvents evaluated. Unexpectedly, the tetrazole form is slightly more stable in $\mathrm{CDCl}_{3}$ when $\mathrm{CX}_{3}$ is bonded at the 7-position of the ring.

Moreover, the ${ }^{15} \mathrm{~N}$ NMR analysis was carried out for compounds $6 \mathbf{a}$ and $6 \mathbf{g}$. The spectra of the phenyl-substituted com- 


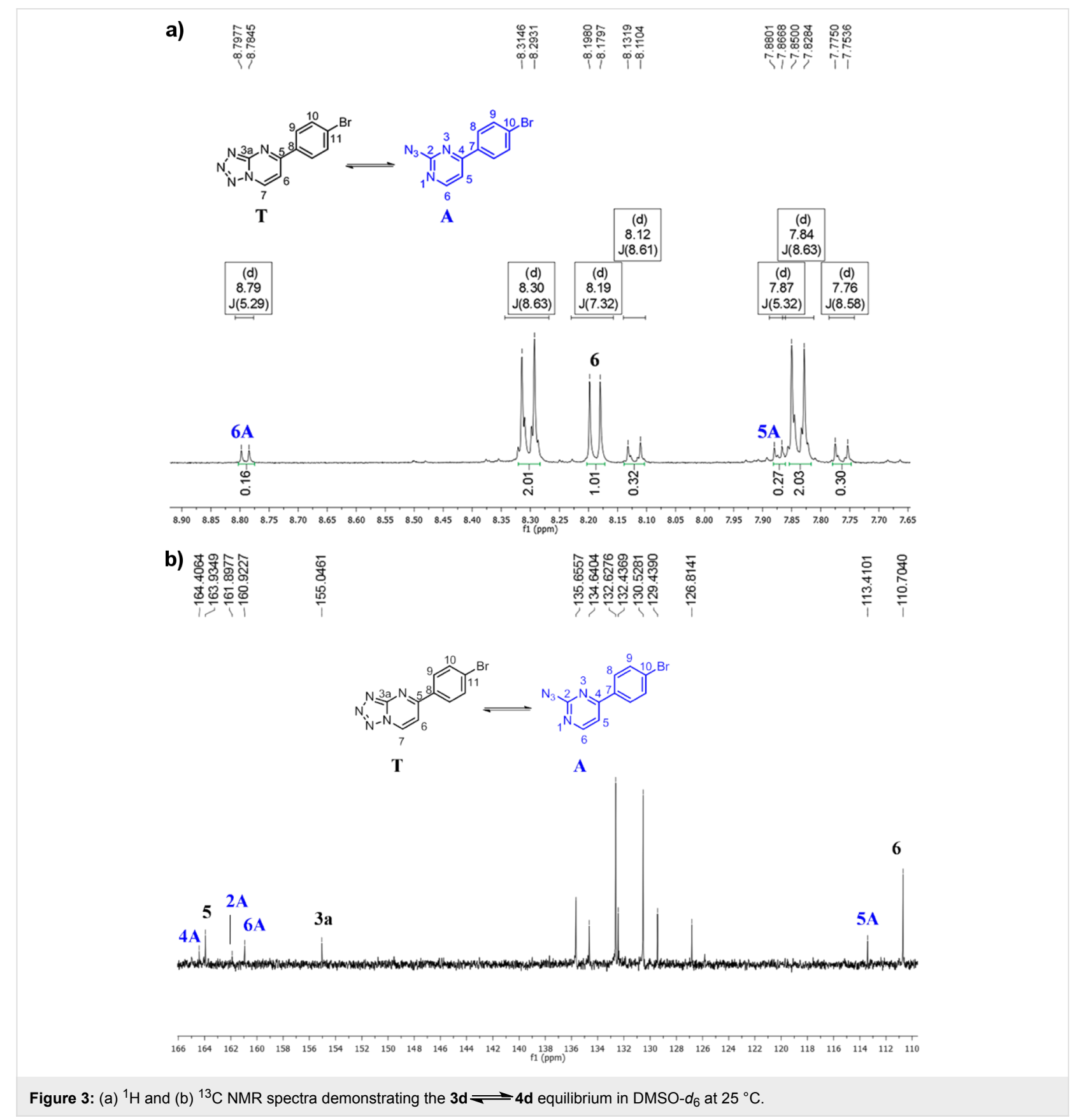

pound $6 \mathbf{a}$, in $\mathrm{CDCl}_{3}$, showed a signal at $\delta 114.8$, which is consistent with $\mathrm{sp}^{3}$ nitrogen. This signal was attributed to N1. The N5, N4, N2, and N3 atoms appear at $\delta 237.1,241.3,252.4$, and 265.7 , respectively. The data obtained from the ${ }^{15} \mathrm{~N}$ NMR spectrum confirms the structure of trifluoromethylated tetrazolo[1,5-a]pyrimidines in solution (See Figures S8 and S9 in Supporting Information File 1) [38-40].

Conversely, in an attempt to extend the studies in this area and to confirm the possibility of the tetrazolo[1,5-a]pyrimidines $\rightleftharpoons 2$-azidopyrimidine equilibrium for trifluoromethyl- ated tetrazolo[1,5-a]pyrimidines in solution, three reactions were planned between phenylacetylene and compounds $\mathbf{6 a - c}$.

The 1,2,3-triazole synthesis from the 1,3-dipolar cycloaddition reaction between $\mathbf{6 a}-\mathbf{c}$ and terminal alkynes catalyzed by copper salts (CuAAC) [41-43] confirms that the reaction passes through an azide intermediate. In addition to mild reaction conditions and short reaction times, the advantage of $\mathrm{CuAAC}$ is the formation of 1,2,3-triazoles-1,4-disubstituted in a highly regioselective manner [41]. Recently, Cornec et al. [44] synthesized 4,6-dimethyl-2-(4-aryl-1H-1,2,3-triazol-1-yl)pyrim- 
Table 3: Structures of trihalomethylated tetrazolo[1,5-a]pyrimidines.

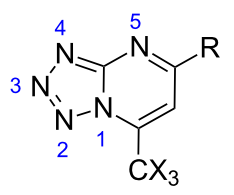

\begin{tabular}{|c|c|c|}
\hline compound & $\mathrm{R}$ & $\mathrm{X}$ \\
\hline $6 a$ & $\mathrm{Ph}$ & $\mathrm{F}$ \\
\hline $6 b$ & $4-\mathrm{Br}-\mathrm{C}_{6} \mathrm{H}_{4}$ & $\mathrm{~F}$ \\
\hline $6 c$ & $4-\mathrm{OCH}_{3}-\mathrm{C}_{6} \mathrm{H}_{4}$ & $\mathrm{~F}$ \\
\hline $6 d$ & $4-\mathrm{F}-\mathrm{C}_{6} \mathrm{H}_{4}$ & $\mathrm{~F}$ \\
\hline $6 e$ & $4-\mathrm{Cl}-\mathrm{C}_{6} \mathrm{H}_{4}$ & $\mathrm{~F}$ \\
\hline $6 f$ & $4-\mathrm{CH}_{3}-\mathrm{C}_{6} \mathrm{H}_{4}$ & $\mathrm{~F}$ \\
\hline $6 \mathrm{~g}$ & $\mathrm{CH}_{3}$ & $\mathrm{~F}$ \\
\hline $6 h^{a}$ & $\mathrm{Ph}$ & $\mathrm{Cl}$ \\
\hline $6 i^{a}$ & $\mathrm{CH}_{3}$ & $\mathrm{Cl}$ \\
\hline
\end{tabular}

aFor synthesis, see Experimental section.

idines from azides using copper salts. The reaction involved the in situ reduction of the $\mathrm{Cu}$ (II) salt by sodium ascorbate.

The reactions in this study were performed from the 1,3dipoloar cycloaddition reaction catalyzed by $\mathrm{Cu}(\mathrm{I})[44]$ and the 1,4-disubstituted 1,2,3-triazoles $\mathbf{8 a - c}$ were acquired in excellent yields (Table 4). Although only compounds $\mathbf{6 a}-\mathbf{c}$ were observed in solution, the different conditions at which the compounds were introduced can induce the establishment of an equilibrium and the presence of an azide in solution. This data indicates that the equilibrium between these two are complex and depend on conditions beyond the nature of the substituent of the tetrazolo $[1,5-a]$ pyrimidines and/or the solvent used to dissolve the compounds.

\section{The equilibrium of tetrazolo[1,5-a]pyrimidine and 2-azidopyrimidine in the solid state}

Furthermore, as observed in the literature, in the solid state or in DMSO- $d_{6}$, the tetrazolo[1,5-a]pyrimidines are favored or predominant in the tetrazolo[1,5-a]pyrimidine $\rightleftharpoons 2$-azidopyrimidine equilibrium [1,21-24,26,27]. Additionally, from quantum mechanical calculations, it was possible to note that compound 3a (tetrazole form) is $1.54 \mathrm{kcal} \mathrm{mol}^{-1}$ more stable than 4a (azide form) in the solid state.

To corroborate this result, compounds $\mathbf{6 a}, \mathbf{b}, \mathbf{d}-\mathbf{f}$ (previously described in reference [37]) were evaluated from the solid state equilibrium point of view (Figure 4). To evaluate the predominant form in the solid state, compounds $\mathbf{6 a}, \mathbf{b}, \mathbf{d}-\mathbf{f}$ - were crystallized and single crystal X-ray diffraction (SCXRD) data were collected. In the solid state, the analysis revealed that the products $\mathbf{6 a}, \mathbf{b}, \mathbf{d}-\mathbf{f}$ are, in fact, in the 2-azidopyrimidine form $\mathbf{7 a}, \mathbf{b}, \mathbf{d}-\mathbf{f}$. It is opposite the trend regarding compound $\mathbf{3 a}$ from DFT data. The ORTEP ${ }^{\circledR}$ plot of 7a is depicted in Figure 4. The ORTEP ${ }^{\circledR}$ plot of $\mathbf{7 b}$ and $\mathbf{7 d}-\mathbf{f}$ can be observed in Figure $\mathrm{S} 10$ in Supporting Information File 1.

Similar to our study, Sirakanyan et al. [46] presented the synthesis and structure of condensed triazolo- and tetrazolopyrimidines, wherein, in DMSO- $d_{6}$, tetrazolo-azidopyrimidines were in equilibrium. However, the structure confirmed by X-ray crystallography was the tetrazole form, which is different from our

Table 4: Reaction conditions $s^{a}$ and yields ${ }^{b}$ of $8 a-c$.<smiles>[R]c1ccc(-c2cc(C(F)(F)F)n3nnnc3n2)cc1</smiles>

$6 a-c$

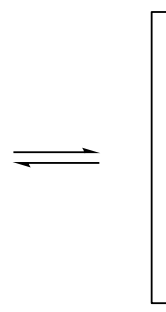

L<smiles>[R]c1ccc(-c2cc(C(F)(F)F)nc(N=N)n2)cc1</smiles>

$7 a-c$<smiles>[R]c1ccc(-c2cc(C(F)(F)F)nc(-n3cc(-c4ccccc4)nn3)n2)cc1</smiles>

$8 \mathbf{a}-\mathbf{c}$

\begin{tabular}{cccc}
\hline product & $\mathrm{R}$ & yield $(\%)^{\mathrm{b}}$ \\
\hline $\mathbf{8 a}$ & $\mathrm{H}$ & 91 \\
$\mathbf{8 b}$ & $\mathrm{Br}$ & 94 \\
$\mathbf{8 c}$ & $\mathrm{OCH}_{3}$ & 93 \\
\hline
\end{tabular}

aReaction conditions: phenylacetylene, $\mathrm{CuSO}_{4} \cdot 2 \mathrm{H}_{2} \mathrm{O}(10 \mathrm{~mol} \%)$, sodium ascorbate $(20 \%)$, tert- $\mathrm{BuOH} / \mathrm{H}_{2} \mathrm{O}(1: 1), 60{ }^{\circ} \mathrm{C}, 24 \mathrm{~h}$. b ${ }^{\circ}$ solated product yield. 


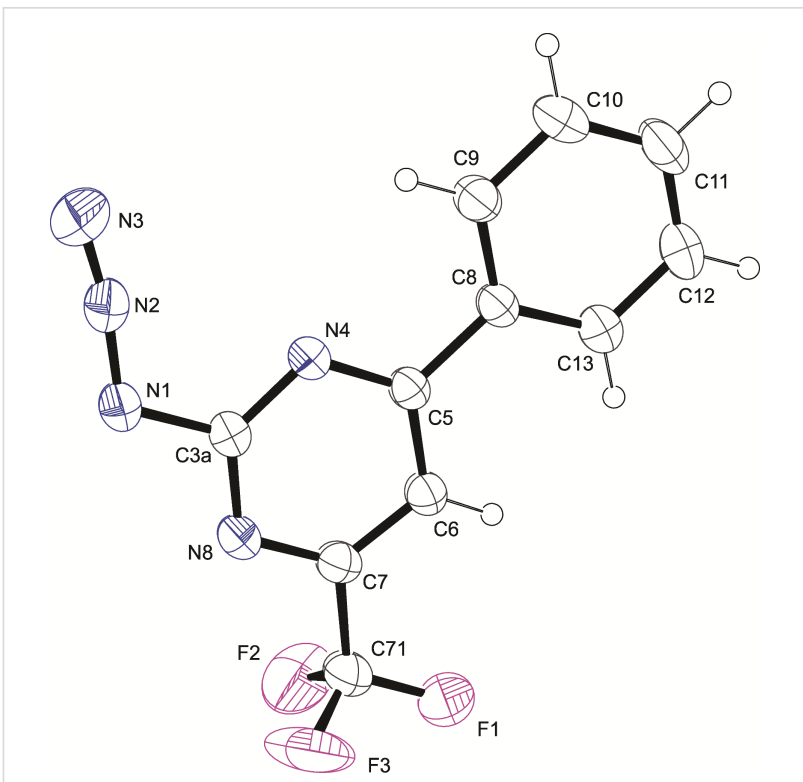

Figure 4: ORTEP ${ }^{\circledR}[45]$ plot of 7 a with thermal ellipsoids drawn at $50 \%$ probability level.

results. This demonstrates how different factors, such as the nature of the substituents and influence of solvents, can change the tetrazole-azide equilibrium.

For this series, when the compounds crystallize (solid form), the equilibrium is shifted to the opened aromatic ring, resulting in a 2-azidopyrimidine compound. The structures of compounds 7a,b and 7f were also confirmed by IR spectroscopy in the solid state. The FTIR spectrum, recorded using a KBr pellet, exhibited a strong absorption band corresponding to the azido group [47] at $2140 \mathrm{~cm}^{-1}$ and $2160 \mathrm{~cm}^{-1}$, thus corroborating the SCXRD results (see Figures S11-S13 in Supporting Information File 1).

Despite the considerable amount of experimental data reported in the literature regarding the azido-tetrazole equilibrium, quantum mechanical studies in this context have yet to be thoroughly explored. This approach provides energy data about the stabilization of the different forms, solvent effects, and shows that the azide-tetrazole transformation is initiated by a $p-\pi$ atomic orbital overlap rather than an electrostatic attraction process [48]. To detect which form is more stable in the solid state, quantum mechanical calculations were performed using the Gaussian 09 software package [35] and B3LYP/cc-pVTZ level of theory for $6 \mathbf{a}$ and $\mathbf{6 g}$. The results suggest that the 2-azidopyrimidine derivatives $\mathbf{7 a - g}$ are about $10 \mathrm{kcal} \mathrm{mol}^{-1}$ more stable than the tetrazolo[1,5-a]pyrimidine derivatives 6a-g. Figure 5 shows the trifluoromethylated tetrazolo[1,5a]pyrimidine structures favored in different conditions in equilibrium.<smiles>[R]c1ccc(-c2cc(C(F)(F)F)n3nnnc3n2)cc1</smiles>

solution<smiles>[R]c1ccc(-c2cc(C(F)(F)F)nc(N)n2)cc1</smiles>

solid state
Figure 5: Tetrazolo[1,5-a]pyrimidine observed in solution $\left(\mathrm{CDCl}_{3}\right.$ and DMSO- $d_{6}$ ) and 2-azidopyrimidine observed in the solid state based on equilibrium.

To support this data, compound $\mathbf{6 h}, \mathbf{i}(\mathrm{X}=\mathrm{Cl})$ was synthesized using the methodology described in [37]. In a $\mathrm{CDCl}_{3}$ or DMSO- $d_{6}$ solution, the compounds $\mathbf{6 h}, \mathbf{i}$ were identified as tetrazolo[1,5-a]pyrimidines (1,5-isomer). Surprisingly, in the solid state (after the crystallization process), compounds $6 \mathbf{i}$ (or $7 \mathbf{i}$ - azide form) were not observed. In this case, the 7-substituted 5-(trichloromethyl)tetrazolo[1,5-a]pyrimidine was found, in which the $\mathrm{CCl}_{3}$ group is bonded at the 5-position of the heterocyclic ring, while $\mathrm{CH}_{3}$ is bound at the 7-position $(\mathbf{8 i}$, Figure 6). The observation was supported by DFT data, in which the tetrazole form was found to be $2.84 \mathrm{kcal} \mathrm{mol}^{-1}$ more stable than its azide form. This indicates that an unusual equilibrium is established for $\mathbf{6} \mathbf{i}$ (i.e., when $\mathrm{R}=\mathrm{CH}_{3}$ ) in the crystallization process (Figure 7). Notwithstanding, $\mathbf{6 h}$ was found in the usual azide form in the solid state $\mathbf{7 h}$ (see Figure S10 in Supporting Information File 1).

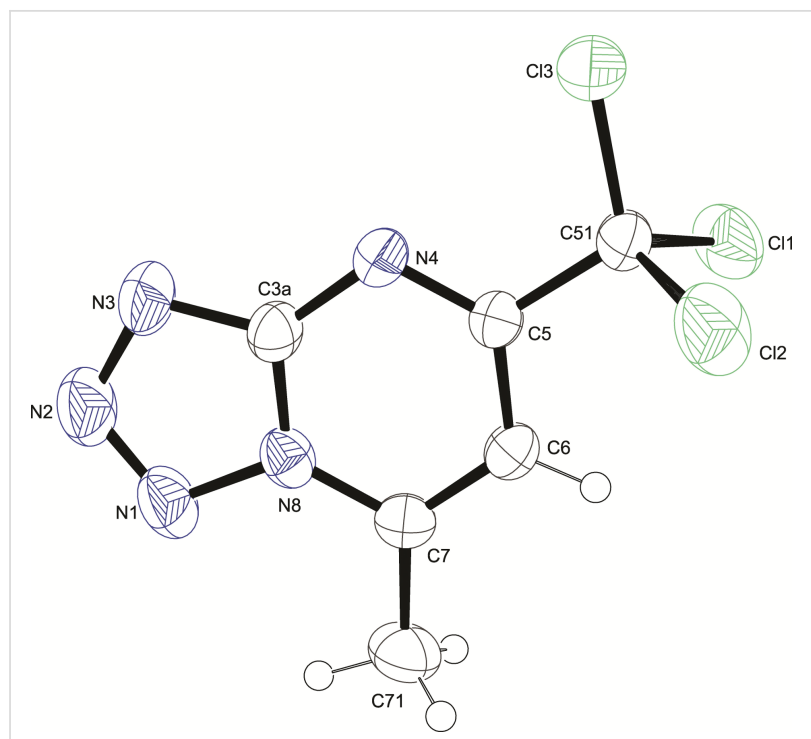

Figure 6: ORTEP ${ }^{\circledR}$ [45] plot of $8 \mathbf{i}$ with thermal ellipsoids drawn at $50 \%$ probability level.

Compound $8 \mathbf{i}$ can be formed when $6 \mathbf{i}$ passes through the azide intermediary $7 \mathbf{i}$ (open ring) due to the presence of the $6 \mathbf{i}: 7 \mathbf{i}$ equilibrium. When the azide form $7 \mathbf{i}$ reacted to tetrazolo $\mathbf{8 i}$, the 


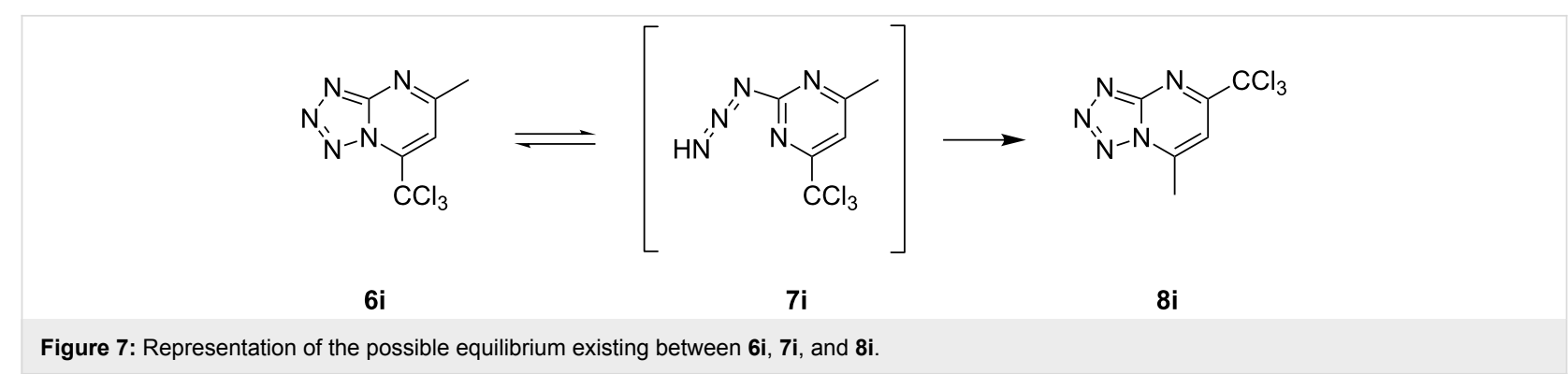

nitrogen atom next to the methyl group participates in the ring closure. This equilibrium was not observed in the other compounds addressed in this work.

In general, tetrazolo $[1,5-a]$ pyrimidines with $7-\mathrm{CF}_{3}$ or $7-\mathrm{CCl}_{3}$ substituents were observed in DMSO- $d_{6}$ or $\mathrm{CDCl}_{3}$, while 2 -azidopyrimidine was found in the solid state. As previously mentioned, the existence of the tetrazolo form in solution can be explained by the presence of electron-withdrawing groups $\left(\mathrm{CX}_{3}\right)$ which stabilize this form. On the other hand, in solid state the azide form (more thermodynamically stable) predominates, except for $\mathbf{8 i}$.

Abu-Eittah et al. [49] theoretically investigated the substituent effect of azidothiazoles in the azido-tetrazole equilibrium using the B3LYP/6-311G** level of theory. Their results showed that electron-withdrawing groups $\left(-\mathrm{NO}_{2},-\mathrm{CN}\right)$ stabilize azide isomers while $-\mathrm{NH}_{2}$ and $-\mathrm{OH}$ groups shift the equilibrium to the tetrazole side. Furthermore, energy calculations demonstrated that tetrazole is less stable than the azide isomer by an amount of energy between 16.02 and $5.44 \mathrm{kcal} \mathrm{mol}^{-1}$. In this case, compounds with $\mathrm{NO}_{2}$ and $\mathrm{NH}_{2}$ substituent has the highest and lowest value, respectively. Coutinho et al. [20] found the same tendency while studying a series of substituents at the 5-position of tetrazolo[1,5-a]pyridines using ab initio calculations. Their findings indicated that electron-withdrawing groups stabilize the azide isomer while electron-donating groups stabilize the tetrazole ring. Additionally, it was observed that $\mathrm{NO}_{2}$ has the largest effect on the equilibrium, stabilizing the azide by $7.0 \mathrm{kcal} \mathrm{mol}^{-1}$ in comparison with the tetrazole. Based on these results, our data are considered to be in accordance with the literature. Therefore, the authors suggest that the $\mathrm{CX}_{3}$ electronwithdrawing groups at the 7-position also present important effects to obtain azide isomers in the solid state $(\mathbf{7 a}, \mathbf{b}, \mathbf{d}-\mathbf{f})$ since, with the exception of $\mathrm{R}=\mathrm{CH}_{3}$ at the 5-position (8i), all the substituents were supplied in the azide form in the solid state.

\section{Conclusion}

A highly regioselective synthesis of triazolo[1,5-a]pyrimidines according to the substituent of the $\beta$-enaminone $\mathbf{1}$ was reported.
All products were obtained in good to excellent yields (40-96\%) and 13 compounds were described for the first time. It was shown that aryl (electron-donating) and $\mathrm{CX}_{3}$ (electronwithdrawing) groups in precursor 1 lead to 5-substituted and 7-substituted triazolo[1,5- $a$ ]pyrimidine compounds, respectively. The results indicate that the reaction regiochemistry is governed by the group bound to the carbonyl of the $\beta$-enaminones. In addition, the tetrazole-azide equilibrium was only detected in solution (DMSO- $d_{6}$ ) for the 1,5-isomers $\mathbf{3 a}-\mathbf{g}: \mathbf{4 a}-\mathbf{g}$. In this case, the predominant form was tetrazole. When $\mathbf{3 d}: 4 \mathbf{d}$ was evaluated in $\mathrm{CDCl}_{3}$, a proportion of 10:90 was observed, which corroborates with predominant forms already described in the literature for triazolo[1,5-a]pyrimidines in both solvents. From the DFT calculations, it was possible to predict that the tetrazole form can be expected in the solid state.

Based on these data, some important insights about the equilibrium in the solid state for 7-trihalomethyl-substituted tetrazolo[1,5-a]pyrimidines were also reported. Unexpectedly, these products were observed predominantly in the tetrazole form $\mathbf{6} \mathbf{a}-\mathbf{h}$ in solution $\left(\mathrm{CDCl}_{3}\right.$ and DMSO- $\left.d_{6}\right)$, while azide species $7 \mathbf{a}-\mathbf{h}$ were observed in the solid state. Notwithstanding, although only the tetrazoles were observed for compounds $\mathbf{6 a - c}$ in solution, the conditions at which the compounds were introduced can induce the equilibrium to favor the presence of the azides (e.g., reaction conditions to achieve $\mathbf{8 a}-\mathbf{c}$ ). In the solid state, the DFT results revealed that the 2-azidopyrimidine derivatives $7 \mathbf{a}-\mathbf{h}$ are approximately $10 \mathrm{kcal} \mathrm{mol}^{-1}$ more stable than tetrazolo $[1,5-a]$ pyrimidine derivatives $\mathbf{6 a}-\mathbf{h}$, which is consistent with the data obtained. This behavior was related to the presence of the $\mathrm{CX}_{3}$ group at the 7-position of the ring. In addition, an unusual equilibrium was observed for compound $\mathbf{6 i}$. The result of $8 \mathbf{i}$ from $\mathbf{6 i}$ crystallization was attributed to the equilibrium $\mathbf{6} \mathbf{i} \rightleftharpoons 7 \mathbf{i}$ (in which $\mathbf{7} \mathbf{i}$ is the azide form).

Lastly, the evaluated series were very important to elucidate the factors that affect the equilibrium in distinct types of tetrazolo[1,5- $a$ pyrimidines in solution or solid state. These results support the substituent influence in both regioselectivity and tetrazole-azide equilibrium of tetrazolo[1,5- $a$ ]pyrimidines with great interest to biological or material sciences. 


\section{Experimental}

The reagents and solvents used were obtained from commercial suppliers without further purification. ${ }^{1} \mathrm{H}$ and ${ }^{13} \mathrm{C}$ NMR spectra were recorded on Bruker DPX $400\left({ }^{1} \mathrm{H}\right.$ at $400.13 \mathrm{MHz}$ and ${ }^{13} \mathrm{C}$ at $100.62 \mathrm{MHz})$ and Bruker DPX-200 $\left({ }^{1} \mathrm{H}\right.$ at $200.13 \mathrm{MHz}$ and ${ }^{13} \mathrm{C}$ at $50.32 \mathrm{MHz}$ ) spectrometers in $\mathrm{CDCl}_{3} / \mathrm{TMS}$ solutions at $298 \mathrm{~K}$ and in DMSO- $d_{6} / \mathrm{TMS}$ solutions at $298 \mathrm{~K}$. All spectra were acquired in a $5 \mathrm{~mm}$ tube at natural abundance. The chemical shifts $(\delta)$ are reported in ppm and $J$ values are given in $\mathrm{Hz}$. The melting points were measured using a Microquímica MQAPF 301 apparatus. The ionic liquid 1-butyl-3-methylimidazolium tetrafluoroborate $[\mathrm{BMIM}]\left[\mathrm{BF}_{4}\right]$ was obtained commercially. The ionic liquid [HMIM][TsO] was prepared according to procedures described in the literature [50]. Additional information regarding the experimental data for the synthesized compounds is presented in Supporting Information File 1.

\section{General procedure for obtaining single crystals}

The single crystals of the compounds were obtained by slow evaporation of the solvents at $25^{\circ} \mathrm{C}$. Compounds $\mathbf{6 a}, \mathbf{b}, \mathbf{f}, \mathbf{h}$, and $\mathbf{8 i}$ were obtained from the solvent $\mathrm{CHCl}_{3}$. Suitable monocrystals for compounds $\mathbf{6 d}, \mathbf{e}$ were obtained from solvent mixtures of ethyl acetate and $\mathrm{EtOH}(3: 2)$.

\section{General procedure for the synthesis of $\beta$-enaminones $\mathbf{1 a - i}$}

$\beta$-Enaminones 1a-i were prepared from the reaction of $N, N$ dimethylformamide dimethylacetal with methyl ketones in accordance with the methodology developed in our laboratory [31].

\section{General procedure for the synthesis of tetrazolo[1,5-a]pyrimidines $\mathbf{3 a - g}, \mathbf{4 a - g}$, and $5 \mathbf{h}, \mathbf{i}$}

A mixture of the 5 -aminotetrazole $(1.0 \mathrm{mmol})$ and the precursor $\beta$-enaminones $1(1.0 \mathrm{mmol})$ in [HMIM][TsO] $(1.0 \mathrm{mmol})$ and $\mathrm{HCl}(0.1 \mathrm{mmol})$ were placed in a round-bottomed flask and magnetically stirred for $5 \mathrm{~min}$ at $120^{\circ} \mathrm{C}$. After cooling, the resulting solid product was washed with water and collected by filtration using a funnel. The obtained products $\mathbf{3 a}-\mathbf{g}, \mathbf{4 a}-\mathrm{g}$, and $\mathbf{5 h}, \mathbf{i}$ were dried using a vacuum pump. Synthesis procedures and experimental data for $\mathbf{3 a}, \mathbf{3 g}, \mathbf{4 a}, \mathbf{4 g}$, and $\mathbf{5 h}$ can also be found in [21,32].

\section{General procedure for the synthesis of (trichloromethyl)tetrazolo[1,5-a]pyrimidines 6h,i}

In a manner closely related to a procedure from [37], a mixture of the 5 -aminotetrazole $(1.0 \mathrm{mmol})$ and the precursor $\beta$-enaminones $1(1.0 \mathrm{mmol})$ in $[\mathrm{BMIM}]\left[\mathrm{BF}_{4}\right](1.0 \mathrm{mmol})$ and $\mathrm{HCl}$
$(0.1 \mathrm{mmol})$ were placed in a round-bottomed flask and magnetically stirred for $6 \mathrm{~h}$ at $120^{\circ} \mathrm{C}$. After the reaction time, chloroform $(30 \mathrm{~mL})$ was added and the resulting mixture was washed with distilled water $(3 \times 10 \mathrm{~mL})$, dried over sodium sulfate $\left(\mathrm{Na}_{2} \mathrm{SO}_{4}\right)$, and the solvent was then removed under reduced pressure. The compounds $\mathbf{6 h}, \mathbf{i}$ were obtained in pure form.

\section{General procedure for the synthesis of tetrazolo[1,5-a]pyrimidines $\mathbf{8 a - c}$}

A mixture of 5-aryl-7-trifluoromethyltetrazolo[1,5-a]pyrimidine 6a-c (1.0 mmol), phenylacetylene (1 mmol), copper sulfate pentahydrate $(10 \mathrm{~mol} \%)$, and sodium ascorbate $(20 \mathrm{~mol} \%)$ in tert-butyl alcohol/water $(1: 1 \mathrm{~mL})$ were placed in a round-bottomed flask and magnetically stirred at $60{ }^{\circ} \mathrm{C}$ for $24 \mathrm{~h}$. After the reaction time was reached, chloroform $(30 \mathrm{~mL})$ was added and the resulting mixture was washed with distilled water $(3 \times 10 \mathrm{~mL})$, dried over sodium sulfate $\left(\mathrm{Na}_{2} \mathrm{SO}_{4}\right)$, and the solvent was then removed under reduced pressure. The compounds $\mathbf{8 a}-\mathbf{c}$ were obtained in pure form.

\section{Supporting Information}

\section{Supporting Information File 1}

Additional material.

[http://www.beilstein-journals.org/bjoc/content/

supplementary/1860-5397-13-237-S1.pdf]

\section{Acknowledgements}

The authors are grateful for the financial support from the National Council for Scientific and Technological Development (CNPq), Research Support Foundation of State of Rio Grande do Sul (FAPERGS) and the Coordination for Improvement of Higher Education Personnel (CAPES/PROEX). The fellowships from CNPq (M. A. P. M., C. R. B., and P.R.S.S.) and CAPES (A.R.M., A.B.P., T.O., G.C.Z.).

\section{ORCID ${ }^{\circledR}$ iDs}

Paulo R. S. Salbego - https://orcid.org/0000-0001-7774-6327 Caroline R. Bender - https://orcid.org/0000-0002-5791-4730 Tainára Orlando - https://orcid.org/0000-0002-4164-4123 Clarissa P. Frizzo - https://orcid.org/0000-0002-1175-7880 Helio G. Bonacorso - https://orcid.org/0000-0002-2745-2061 Nilo Zanatta - https://orcid.org/0000-0002-0959-9043

\section{References}

1. Raju, C.; Madhaiyan, K.; Uma, R.; Sridhar, R.; Ramakrishna, S. RSC Adv. 2012, 2, 11657-11663. doi:10.1039/c2ra21330c

2. Aly, A. A. Phosphorus, Sulfur Silicon Relat. Elem. 2006, 181, 1285-1298. doi:10.1080/10426500500326792 
3. Nagai, S.-I.; Ueda, T.; Sugiura, S.; Nagatsu, A.; Murakami, N.; Sakakibara, J.; Fujita, M.; Hotta, Y. J. Heterocycl. Chem. 1998, 35, 325-327. doi:10.1002/jhet.5570350211

4. Uehata, M.; Ono, T.; Satoh, H.; Yamagami, K.; Kawahara, T. Medicines Comprising Rho Kinase Inhibitor. U.S. Patent US 6,218,410 B1, April 17, 2001.

5. Aspnes, G. E.; Chiang, Y.-C. P. Tetrazole Compounds as Thyroid Receptor Ligands. U.S. Patent US 6,441,015 B2, Aug 27, 2002.

6. Fujii, A.; Tanaka, H.; Otsuki, M.; Kawaguchi, T.; Oshita, K. Antitumor effect potentiators. U.S. Patent US 6,930,115 B2, Aug 16, 2005.

7. Takayama, Y.; Yoshida, Y.; Uehata, M. Visual Function Disorder Improving Agents. U.S. Patent US 007109208 B2, Sept 19, 2006.

8. Hussein, A. M.; Ahmed, O. M. Bioorg. Med. Chem. 2010, 18, 2639-2644. doi:10.1016/j.bmc.2010.02.028

9. Hussein, A. M. J. Saudi Chem. Soc. 2010, 14, 61-68. doi:10.1016/j.jscs.2009.12.010

10. Takao Takaya, K.; Masayoshi Murata, O.; Kiyotaka Ito, I. Pyrimidine Compounds Having Activity as a Cardiotonic Anti-Hypertensive Cerebrovascular Vasodilator and Anti-Platelet Aggregation Agent. U.S. Patent US 4,725,600, Feb 16, 1988.

11. Utsunomiya, T.; Niki, T.; Kikuchi, T.; Watanabe, J.; Yamagishi, K.; Nishioka, M.; Suzuki, H.; Furusato, T.; Miyake, T. Tetrazole Compounds and Pest Control Agent. WO Patent WO 1999006380 A1, Feb 11, 1999

12. Abelman, M.; Jiang, R.; Zablocki, J. Substituted heterocyclic compounds. U.S. Patent US 2009/0181986 A1, July 16, 2009.

13. Dougherty, A. M.; Guo, H.; Westby, G.; Liu, Y.; Simsek, E.; Guo, J.-T.; Mehta, A.; Norton, P.; Gu, B.; Block, T.; Cuconati, A. Antimicrob. Agents Chemother. 2007, 51, 4427-4437. doi:10.1128/AAC.00541-07

14. Raju, C.; Kalaipriya, M.; Uma, R.; Sridhar, R.; Ramakrishna, S. Curr. Chem. Lett. 2012, 1, 27-34. doi:10.5267/j.ccl.2011.12.004

15. Zeng, L.-Y.; Cai, C. J. Comb. Chem. 2010, 12, 35-40. doi:10.1021/cc9000983

16. Yao, C.; Lei, S.; Wang, C.; Yu, C.; Tu, S. J. Heterocycl. Chem. 2008, 45, 1609-1613. doi:10.1002/jhet.5570450609

17. Ghorbani-Vaghei, R.; Toghraei-Semiromi, Z.; Amiri, M.; Karimi-Nami, R. Mol. Diversity 2013, 17, 307-318. doi:10.1007/s11030-013-9435-0

18. Desenko, S. M.; Gladkov, E. S.; Komykhov, S. A.; Shishkin, O. V.; Orlov, V. D. Chem. Heterocycl. Compd. 2001, 37, 747-754. doi:10.1023/A:1011925631511

19. Gein, V. L.; Gein, L. F.; Tsyplyakova, E. P.; Panova, O. S. Russ. J. Org. Chem. 2007, 43, 1382-1386. doi:10.1134/S1070428007090205

20. Kanyalkar, M.; Coutinho, E. C. Tetrahedron 2000, 56, 8775-8777. doi:10.1016/S0040-4020(00)00819-X

21. Krivopalov, V. P.; Mamatyuk, V. I.; Nikolaenkova, E. B. Russ. Chem. Bull. 1995, 44, 1435-1443. doi:10.1007/BF00714425

22. Bajwa, J. S.; Sykes, P. J. J. Chem. Soc., Perkin Trans. 11979 , 3085-3094. doi:10.1039/p19790003085

23. Cubero, E.; Orozco, M.; Luque, F. J. J. Am. Chem. Soc. 1998, 120, 4723-4731. doi:10.1021/ja9726724

24. Temple, C., Jr.; McKee, R. L.; Montgomery, J. A. J. Org. Chem. 1962, 27, 1671-1673. doi:10.1021/jo01052a045

25. Boyer, J.; Hyde, H. J. Org. Chem. 1960, 25, 458-459. doi:10.1021/jo01073a608

26. Temple, C., Jr.; Thorpe, M. C.; Coburn, W. C., Jr.; Montgomery, J. A. J. Org. Chem. 1966, 31, 935-938. doi:10.1021/jo01341a071
27. Temple, C., Jr.; Montgomery, J. A. J. Org. Chem. 1965, 30, 826-829. doi:10.1021/jo01014a041

28. Pochinok, V. Y.; Avramenko, L. F.; Grigorenko, P. S.; Skopenko, V. N. Russ. Chem. Rev. 1975, 44, 481-492. doi:10.1070/RC1975v044n06ABEH002355

29. Martins, M. A. P.; Scapin, E.; Frizzo, C. P.; Rosa, F. A.; Bonacorso, H. G.; Zanatta, N. J. Braz. Chem. Soc. 2009, 20, 205-213. doi:10.1590/S0103-50532009000200003

30. Frizzo, C. P.; Scapin, E.; Marzari, M. R. B.; München, T. S.; Zanatta, N.; Bonacorso, H. G.; Buriol, L.; Martins, M. A. P. Ultrason. Sonochem. 2014, 21, 958-962. doi:10.1016/j.ultsonch.2013.12.007

31. Martins, M. A. P.; Frizzo, C. P.; Moreira, D. N.; Rosa, F. A.; Marzari, M. R. B.; Zanatta, N.; Bonacorso, H. G. Catal. Commun. 2008, 9, 1375-1378. doi:10.1016/j.catcom.2007.11.037

32. Krasovsky, A. L.; Moiseev, A. M.; Nenajdenko, V. G.; Balenkova, E. S. Synthesis 2002, 901-905. doi:10.1055/s-2002-28512

33. Shao, Y.; Zhu, K.; Qin, Z.; Li, E.; Li, Y. J. Org. Chem. 2013, 78, 5731-5736. doi:10.1021/j04005553

34. Xu, H.; Zhou, B.; Zhou, P.; Zhou, J.; Shen, Y.; Yu, F.-C.; Lu, L.-L. Chem. Commun. 2016, 52, 9471-9472. doi:10.1039/C6CC90308H

35. Gaussian 09, Revision A.02; Gaussian, Inc.: Wallingford CT, 2016.

36. Sirakanyan, S. N.; Spinelli, D.; Geronikaki, A.; Kartsev, V. G.; Panosyan, H. A.; Ayvazyan, A. G.; Tamazyan, R. A.; Frenna, V.; Hovakimyan, A. A. Tetrahedron 2016, 72, 1919-1927. doi:10.1016/j.tet.2016.02.048

37. Scapin, E.; Frizzo, C. P.; Rodrigues, L. V.; Zimmer, G. C.; Vaucher, R. A.; Sagrillo, M. R.; Giongo, J. L.; Afonso, C. A. M.; Rijo, P.; Zanatta, N.; Bonacorso, H. G.; Martins, M. A. P. Med. Chem. Res. 2017, 26, 640-649. doi:10.1007/s00044-017-1783-3

38. Shestakova, T. S.; Shenkarev, Z. O.; Deev, S. L.; Chupakhin, O. N.; Khalymbadzha, I. A.; Rusinov, V. L.; Arseniev, A. S. J. Org. Chem. 2013, 78, 6975-6982. doi:10.1021/jo4008207

39. Cmoch, P.; Stefaniak, L.; Webb, G. A. Magn. Reson. Chem. 1997, 35, 237-242. doi:10.1002/(SICI)1097-458X(199704)35:4<237::AID-OMR63>3.0.CO; 2-L

40. Cmoch, P. Magn. Reson. Chem. 2002, 40, 507-516. doi:10.1002/mrc.1055

41. Rostovtsev, V. V.; Green, L. G.; Fokin, V. V.; Sharpless, K. B. Angew. Chem., Int. Ed. 2002, 41, 2596-2599. doi:10.1002/1521-3773(20020715)41:14<2596::AID-ANIE2596>3.0.CO ;2-4

42. Hein, J. E.; Fokin, V. V. Chem. Soc. Rev. 2010, 39, 1302-1315. doi:10.1039/b904091a

43. Tornøe, C. W.; Christensen, C.; Meldal, M. J. Org. Chem. 2002, 67, 3057-3064. doi:10.1021/jo011148j

44. Cornec, A.-S.; Baudequin, C.; Fiol-Petit, C.; Plé, N.; Dupas, G.; Ramondenc, Y. Eur. J. Org. Chem. 2013, 1908-1915. doi:10.1002/ejoc.201201033

45. Farrugia, L. J. J. Appl. Crystallogr. 1997, 30, 565. doi:10.1107/S0021889897003117

46. Sirakanyan, S. N.; Geronikaki, A.; Spinelli, D.; Hovakimyan, A. A.; Noravyan, A. S. Tetrahedron 2013, 69, 10637-10643. doi:10.1016/j.tet.2013.10.015

47. Bajwa, J. S.; Sykes, P. J. J. Chem. Soc., Perkin Trans. 1 1980, 1019-1024. doi:10.1039/p19800001019

48. Abu-Eittah, R. H.; El-Taher, S.; Hassan, W. M. I.; Noamaan, M. A. Comput. Theor. Chem. 2014, 1033, 52-59. doi:10.1016/j.comptc.2014.01.024 
49. Abu-Eittah, R. H.; El-Kelany, K. E. Spectrochim. Acta, Part A 2012, 99, 316-328. doi:10.1016/j.saa.2012.08.012

50. Zhao, G.; Jiang, T.; Gao, H.; Han, B.; Huang, J.; Sun, D. Green Chem. 2004, 6, 75-77. doi:10.1039/b309700p

\section{License and Terms}

This is an Open Access article under the terms of the Creative Commons Attribution License

(http://creativecommons.org/licenses/by/4.0), which permits unrestricted use, distribution, and reproduction in any medium, provided the original work is properly cited.

The license is subject to the Beilstein Journal of Organic Chemistry terms and conditions:

(http://www.beilstein-journals.org/bjoc)

The definitive version of this article is the electronic one which can be found at:

doi:10.3762/bjoc. 13.237 